Vol 12, Issue 12, 2019

\title{
STUDY ON THE ASSOCIATION OF OBESITY INDICES WITH INFLAMMATORY MARKERS IN PRE-DIABETES AND DIABETES
}

\author{
PRADEEP KUMAR ${ }^{1}$, SHAILAZA SHRESTHA ${ }^{1}$, MAHENDRA PRASAD ${ }^{2}$, PREETI SHARMA ${ }^{1 *}$, MOHIT ${ }^{3}$
}

${ }^{1}$ Department of Biochemistry, Santosh Medical College and Hospital, Ghaziabad, Uttar Pradesh, India. ${ }^{2}$ Department of Biochemistry, Heritage Institute of Medical Sciences, Varanasi, Uttar Pradesh, India. ${ }^{3}$ Department of Biochemistry, Autonomous State Medical College and Hospital, Basti, Uttar Pradesh, India. Email: prcdri2003@yahoo.co.in

Received: 04 September 2019, Revised and Accepted: 11 October 2019

ABSTRACT

Objective: In this study, the main objective was to evaluate the association of markers of obesity with the inflammatory markers in pre-diabetes and diabetes.

Methods: This study recruited 300 participants (100 control group, 100 pre-diabetic group, and 100 diabetic group). The anthropometric variables such as body mass index (BMI), waist-hip ratio (WHR), and waist circumference (WC), and biochemical variables such as fasting blood glucose, glycated hemoglobin, uric acid, C-reactive protein (CRP), fibrinogen, interleukin-6 (IL-6), and adiponectin were analyzed in each participant by standard methods.

Results: The present study documented significantly high values of BMI and WHR in patient (pre-diabetic and diabetic) groups compared to the control group. Similarly, the level of adiponectin decreased and that of uric acid, CRP, fibrinogen, and IL- 6 increased significantly. Both BMI and WC were correlated significantly with inflammatory mediators in diabetic patients. The correlation with adiponectin was negative. In the pre-diabetic group, a significant correlation was observed only between WHR, adiponectin, and uric acid.

Conclusion: This study supports the fact that obesity-induced systemic inflammation of low grade is significantly associated with pre-diabetes and diabetes, thereby keeping these individuals at high risk of future complications especially cardiovascular diseases.

Keywords: Obesity, Inflammation, Pre-diabetes, Diabetes.

(C) 2019 The Authors. Published by Innovare Academic Sciences Pvt Ltd. This is an open access article under the CC BY license (http://creativecommons. org/licenses/by/4. 0/) DOI: http://dx.doi.org/10.22159/ajpcr.2019.v12i12.35588

\section{INTRODUCTION}

Since the past few decades, an increasing trend in the incidence of obesity has been observed. Before Hippocrates who categorized obesity as a medical disorder, obesity was merely regarded as a cosmetic problem. Later, researches documented obesity as the causative agent to various abnormalities such as dyslipidemia, hypertension, diabetes, metabolic syndrome, and cardiovascular diseases (CVDs) [1]. Diabetes mellitus, a metabolic disorder induced by insulin resistance [2], is one of the serious outcomes of obesity. According to different animal studies, brown adipose tissue is chiefly involved in glucose and energy homeostasis [3], while white adipose tissue especially visceral type is the source of inflammatory mediators such as adiponectin, tumor necrosis factor- $\alpha$, interleukin-6 (IL-6), and leptin [4].

The previous studies have reported increased expression of proinflammatory cytokines in obesity, thereby suggesting the link between inflammation, obesity, and its associated complications [5]. As individual progresses to obesity, the adipocytes become hypertrophic and hyperplastic with a consequent reduction in blood supply leading to hypoxia that incites infiltration of macrophages into and necrosis of adipocytes causing the production of pro-inflammatory molecules in the excess amount [6]. Alterations in adipocyte physiology unhinge its anti-inflammatory and pro-inflammatory secretory balance, thereby favoring dysglycemia which on the long-term leads to diabetes and cardiovascular complications [7].

Diabetes development follows a dormant pre-diabetic phase which though is a hyperglycemic state is characterized by glycemia above and below the range of normal and diabetic state [8]. Pre-diabetes is also associated with overweight, obesity, and inflammatory phenomenon. Pre-diabetic subjects are not only at a high risk of future diabetes but also are at the high propensity of cardiovascular complications mediated by obesity and inflammation. Thus, regular monitoring of adipokines may be useful in selecting these mediators as therapeutic targets to decrease obesity incidences and its associated risks in hyperglycemic patients. Thus, this study was put forth to evaluate the association of obesity indices (body mass index [BMI], waist circumference [WC], and waist-hip ratio [WHR]) with inflammatory mediators in pre-diabetic and diabetic subjects. Furthermore, there is the paucity of studies correlating the mediators of obesity with inflammatory mediators in Indian population.

\section{METHODS}

This present study was an observational case-control study with 100 of each pre-diabetic and diabetic subjects. A total of 100 healthy volunteers were recruited as a control group.

\section{Inclusion criteria}

The patients clinically diagnosed as pre-diabetic and diabetic as per the WHO criteria (Table 1) were recruited.

\section{Exclusion criteria}

Patients unwilling to participate, patients with type 1 diabetes, heart disease, liver disease, renal disease, malignancy, pregnancy, or any inflammatory states were excluded from the study.

Sample collection and processing

After obtaining ethical approval (from the institute) and written consent (from participants), fasting blood sample was collected in fluoride vial 
(for glucose estimation), plain vial (for estimation of inflammatory molecules such as adiponectin, uric acid, CRP and IL-6), and EDTA vial (for fibrinogen and glycated hemoglobin estimation). The samples were centrifuged and the serum or plasma collected was kept at $-80^{\circ} \mathrm{C}$ until the day of analysis.

\section{Anthropometric measurements}

The anthropometric variables included in the present study were BMI, WHR, and WC. For the estimation of BMI, the height (in $\mathrm{cm}$ ) was measured using stadiometer with the participants standing barefoot. Weight (in $\mathrm{kg}$ ) was measured using a balanced weight measurement scale. Then, the BMI was calculated as:

$$
\mathrm{BMI}=\frac{\text { Weight }(\mathrm{kg})}{\text { Height }\left(\mathrm{m}^{2}\right)}
$$

Based on BMI value, the participants were grouped as:

- Normal $\rightarrow 18.5-24.9$

- $\quad$ Overweight $\rightarrow 25-29.9$

- $\quad$ Obese $\rightarrow \geq 30$.

The WC and hip circumference were measured using a measuring tape.

- WC: Measured midway between last rib and iliac crest

- Hip circumference: Measured around the widest part of the hip.

The WHR was calculated as:

$$
\text { WHR }=\frac{\text { Waist circumference }(\mathrm{cm})}{\text { Hip circumference }(\mathrm{cm})}
$$

Based on WHR, the participants were categorized into groups, namely participants with WHR $<0.9$ and WHR $>0.9$ (as per WHO criteria). Similarly, based on WC, the participants were group as those with WC $\leq 90$ and those with WC $>90$ (as per International Diabetes Federation cutoff points for South Asians) [1].

\section{Assay of biochemical parameters}

Biochemical analytes such as glucose, HbA1c (glycated hemoglobin), uric acid, CRP, IL-6, fibrinogen, and adiponectin were estimated by commercially available standard kits.

Table 1: Diagnostic criteria for pre-diabetes and diabetes

\begin{tabular}{llll}
\hline Case & Normal & Pre-diabetes & Diabetes \\
\hline $\begin{array}{l}\text { Fasting blood } \\
\text { glucose }\end{array}$ & $60-100 \mathrm{mg} / \mathrm{dL}$ & $101-125 \mathrm{mg} / \mathrm{dL}$ & $\geq 126 \mathrm{mg} / \mathrm{dL}$ \\
$\begin{array}{l}\text { Post prandial } \\
\text { blood glucose }\end{array}$ & $101-140 \mathrm{mg} / \mathrm{dL}$ & $141-199 \mathrm{mg} / \mathrm{dL}$ & $\geq 200 \mathrm{mg} / \mathrm{dL}$ \\
$\begin{array}{l}\text { Glycated } \\
\text { hemoglobin }\end{array}$ & $<5.7 \%$ & $5.7-6.3 \%$ & $\geq 6.4 \%$ \\
\hline
\end{tabular}

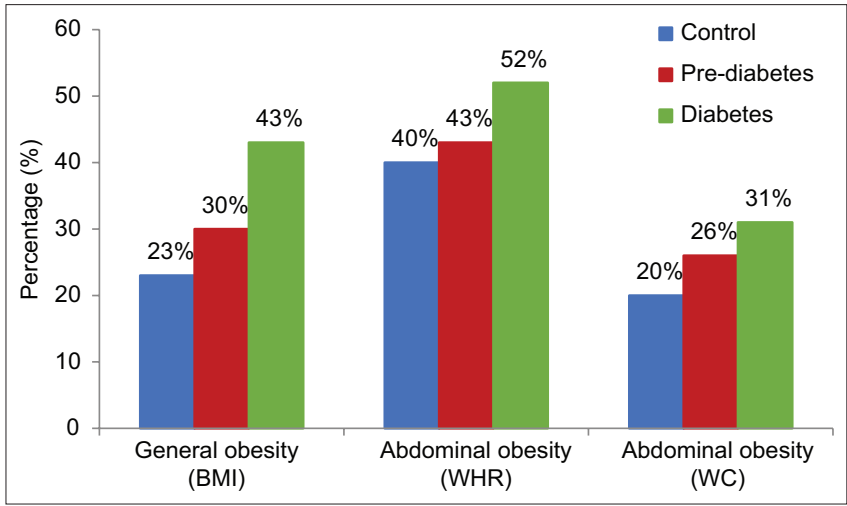

Fig. 1: Incidence of obesity in control, pre-diabetes, and diabetes
- $\quad$ Fasting blood glucose (FBG) $\rightarrow$ GODPOD (glucose oxidase-peroxidase) method

- HbA1c $\rightarrow$ Ion exchange resin method

- Uric acid $\rightarrow$ Uricase method

- $\quad$ Fibrinogen and CRP $\rightarrow$ Immunoturbidimetric method

- IL-6 and adiponectin $\rightarrow$ Enzyme-linked immunoadsorbent assay.

\section{Statistical analysis}

The values were represented in terms of mean \pm standard deviation. The comparative analysis was done by Student's t-test. Pearson's correlation coefficient was calculated to determine the association between the variables. $\mathrm{p}<0.05$ indicated statistical significance.

\section{RESULTS}

In this study, 300 participants were enrolled who were categorized into three groups involving 100 each of control group, pre-diabetic group, and diabetic group. The incidence of obesity (general and abdominal) in each group was determined (Fig. 1). General obesity was indicated in terms of BMI $\geq 25$ while abdominal obesity was represented in terms of WHR $\geq 0.9$ and $\mathrm{WC}>90 \mathrm{~cm}$. The prevalence of obesity increased from control-prediabetic-diabetic categories (i.e., 23\%, 30\%, and 43\%; 40\%, $43 \%$, and $52 \%$; and $20 \%, 26 \%$, and $31 \%$, respectively)

In Table 2, demographic variables (age, BMI, WHR, and WC) and biochemical variables (FBG, HbA1c, uric acid, CRP, fibrinogen, IL- 6, and adiponectin) were compared between the study groups. Significantly, high values of demographic variables were found as the groups progressed from normoglycemia to hyperglycemia. There was also a significant elevation in FBG, $\mathrm{HbA} 1 \mathrm{c}$, inflammatory variables (uric acid, CRP, fibrinogen, and IL-6) and a significant decrease in an anti-inflammatory variable (adiponectin) when the comparison was made between control/pre-diabetes and control/diabetes groups. The mean values of serum adiponectin were $8.7 \pm 2.6 \mu \mathrm{g} / \mathrm{mL}$, $8.09 \pm 1.94 \mu \mathrm{g} / \mathrm{mL}$, and $6.74 \pm 1.89 \mu \mathrm{g} / \mathrm{mL}$ for control, pre-diabetes, and diabetes, respectively. Likewise, the mean values of uric acid, CRP, fibrinogen, and IL- 6 were $4.49 \pm 0.75 \mathrm{mg} / \mathrm{dL}, 4.71 \pm 1.04 \mathrm{mg} / \mathrm{dL}$, and $6.33 \pm 2.6 \mathrm{mg} / \mathrm{dL} ; 2.77 \pm 1.18 \mathrm{mg} / \mathrm{mL}, 4.29 \pm 1.39 \mathrm{mg} / \mathrm{mL}$, and $5.12 \pm 1.68 \mathrm{mg} / \mathrm{mL} ; 3.32 \pm 0.58 \mathrm{mg} / \mathrm{mL}, \quad 4.49 \pm 0.55 \mathrm{mg} / \mathrm{mL}$, and $3.76 \pm 0.62 \mathrm{mg} / \mathrm{mL}$; and $4.41 \pm 1.87 \mathrm{pg} / \mathrm{mL}, 5.93 \pm 1.91 \mathrm{pg} / \mathrm{mL}$, and $7.65 \pm 2.26 \mathrm{pg} / \mathrm{mL}$, respectively, for control, pre-diabetic, and diabetic groups.

The obesity indices were correlated with inflammatory variables as shown in Tables 3 and 4. Among pre-diabetic patients, a significant inverse association was established between adiponectin and WHR $(\mathrm{r}=-0.23, \mathrm{p}<0.05)$ only while the correlations of rest variables were insignificant $(\mathrm{p}>0.05)$. Among the diabetic patients, BMI correlated significantly with CRP $(r=0.4, p<0.05)$, IL-6 ( $r=0.34, p<0.5)$, and adiponectin $(\mathrm{r}=-0.49, \mathrm{p}<0.05)$ while WC was correlated with all other inflammatory variables except uric acid $(r=0.1, p>0.05$ for uric acid; $\mathrm{r}=0.33, \mathrm{p}<0.05$ for CRP; $\mathrm{r}=0.25, \mathrm{p}<0.05$ for IL-6; $\mathrm{r}=0.22, \mathrm{p}<0.05$ for fibrinogen; and $r=-0.31, p<0.05$ for adiponectin) but the correlation of WHR with these markers was insignificant ( $p>0.05)$.

The levels of inflammatory variables were also evaluated at different degrees of BMI, WHR, and WC. The pattern observed was a decrease in the level of adiponectin and an increase in the level of uric acid, CRP, fibrinogen, and IL- 6 with the increase in the degree of obesity indices (Figs. 2-7).

\section{DISCUSSION}

Changes in living style due to urbanization have arisen a major global concern called obesity that leads to several metabolic complications. Obesity chiefly measured by BMI is a well-characterized risk factor of diabetes [9]. Increased BMI is suggestive of general or overall obesity while visceral or abdominal obesity is suggestive of increased WHR and WC. Now, it is widely accepted that visceral obesity plays a pivotal role in mediating insulin resistance that finally culminates in diabetes 
Table 2: Comparison of study variables among the participants

\begin{tabular}{|c|c|c|c|}
\hline Parameter & Control & Pre-diabetes & Diabetes \\
\hline Age (years) & $42.67 \pm 7.66^{\mathrm{a} * *}$ & $47.39 \pm 6.85^{c * *}$ & $50.6 \pm 9.89^{\mathrm{b} * *}$ \\
\hline BMI & $23.52 \pm 2.14^{\mathrm{a}}$ & $23.82 \pm 2.45^{c *}$ & $24.49 \pm 2.67^{\mathrm{b} *}$ \\
\hline WC $(\mathrm{cm})$ & $0.86 \pm 0.08^{\mathrm{a}}$ & $0.89 \pm 0.1^{c}$ & $0.9 \pm 0.12^{\mathrm{b}}$ \\
\hline WHR & $0.85 \pm 0.08^{\mathrm{a} *}$ & $0.89 \pm 0.11^{\mathrm{c}}$ & $0.89 \pm 0.12^{\mathrm{b} *}$ \\
\hline FBG (mg/dL) & $82.33 \pm 7.52^{\mathrm{a} * *}$ & $116.42 \pm 5.12^{\mathrm{c} * *}$ & $158.93 \pm 36.58^{\mathrm{b} * *}$ \\
\hline HbA1c (gm\%) & $4.99 \pm 0.52^{a * *}$ & $5.86 \pm 0.42^{\mathrm{c} * *}$ & $6.33 \pm 0.81^{\mathrm{b} * *}$ \\
\hline Uric Acid (mg/dL) & $4.49 \pm 0.75^{\mathrm{a}}$ & $4.71 \pm 1.04^{\mathrm{c**}}$ & $6.33 \pm 1.88^{\mathrm{b} * *}$ \\
\hline IL-6 $(\mathrm{pg} / \mathrm{mL})$ & $4.4 \pm 1.87^{\mathrm{a} * *}$ & $5.93 \pm 1.61^{\mathrm{c**}}$ & $7.65 \pm 2.26^{\mathrm{b} * *}$ \\
\hline Fibrinogen (mg/mL) & $3.32 \pm 0.58^{\mathrm{a} *}$ & $3.49 \pm 0.55^{\mathrm{c} * *}$ & $3.76 \pm 0.62^{\mathrm{b} * *}$ \\
\hline Adiponectin $(\mu \mathrm{g} / \mathrm{mL})$ & $8.7 \pm 2.66^{\mathrm{a} *}$ & $8.09 \pm 1.94^{\mathrm{c} * *}$ & $6.74 \pm 1.89^{\mathrm{b} * *}$ \\
\hline
\end{tabular}

$* \rightarrow p<0.05$ and ${ }^{* *} \rightarrow p<0.01$. $a \rightarrow$ Control versus pre-diabetes $b \rightarrow$ Control versus diabetes $\mathrm{c} \rightarrow$ Pre-diabetes versus diabetes. BMI: Body mass index, WC: Waist circumference, WHR: Waist-hip ratio, FBG: Fasting blood glucose, CRP: C-reactive protein, IL-6: Interleukin-6, HbA1c: Glycated hemoglobin

Table 3: Correlation of obesity indices with inflammatory mediators in pre-diabetes

\begin{tabular}{llll}
\hline Parameter (P) & r (BMI) & r (WHR) & r (WC) \\
\hline Uric acid & 0.16 & $0.25^{*}$ & 0.2 \\
CRP & 0.02 & 0.07 & 0.06 \\
IL-6 & 0.05 & 0.04 & 0.07 \\
Fibrinogen & 0.1 & 0.12 & 0.09 \\
Adiponectin & -0.12 & $-0.23^{*}$ & -0.16 \\
\hline
\end{tabular}

${ }_{*}^{*} \rightarrow \mathrm{p}<0.05$. BMI: Body mass index, WC: Waist circumference, WHR: Waist-hip ratio, CRP: C-reactive protein, IL-6: Interleukin-6

Table 4: Correlation of obesity indices with inflammatory mediators in diabetes

\begin{tabular}{llll}
\hline Parameter (D) & r (BMI) & r (WHR) & r (WC) \\
\hline Uric acid & 0.2 & 0.09 & 0.1 \\
CRP & $0.41^{*}$ & 0.15 & $0.33^{*}$ \\
IL-6 & $0.34^{*}$ & 0.2 & $0.25^{*}$ \\
Fibrinogen & 0.1 & 0.05 & $0.22^{*}$ \\
Adiponectin & $0.49^{*}$ & -0.18 & $-0.31^{*}$ \\
\hline
\end{tabular}

$* \rightarrow p<0.05$. BMI: Body mass index, WC: Waist circumference, WHR: Waist-hip ratio, CRP: C-reactive protein, IL-6: Interleukin-6

mellitus [10]. Increased obesity also predisposes individuals to future risk of CVDs and the risk is further amplified in pre-diabetic and diabetic patients.

Obesity is associated with low-grade inflammation due to the expansion of adipose tissue chiefly of visceral origin. The presence of abnormal adipocytes at ectopic sites affects overall body metabolism. Further, the infiltration of macrophages in adipose tissues stimulates hepatic insulin resistance and chronic inflammation [11]. Several studies have confirmed the fact that low-grade inflammation for a prolonged duration with an increase in circulating inflammatory markers will facilitate the development of pre-diabetes and diabetes. It is also a wellknown fact that most of the pre-diabetic individuals finally progress to diabetes; however, the individuals who are overweight or obese with sedentary life are more prone to progress. Since the inflammatory milieu is mechanistically involved in this vicious cycle, in the present study an effort was made to evaluate the association of obesity indices (BMI, WHR, and WC) with inflammatory mediators in pre-diabetes and diabetes.

In this study, an increased prevalence of obesity (general and abdominal) was observed in the pre-diabetic group and diabetic group compared to the control group. About 30\% of pre-diabetic and $43 \%$ of diabetic patients exhibited general obesity, while $43 \%$ and $26 \%$ of pre-diabetic patients, and $52 \%$ and $31 \%$ of diabetic patients showed abdominal obesity in terms of WHR and WC, respectively. The previous studies also reported higher incidences of obesity in hyperglycemic

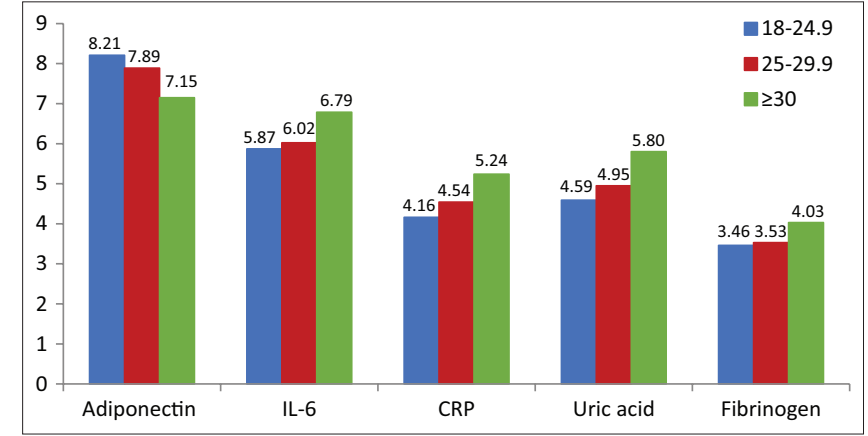

Fig. 2: Effect of body mass index on the level of inflammatory markers in pre-diabetes

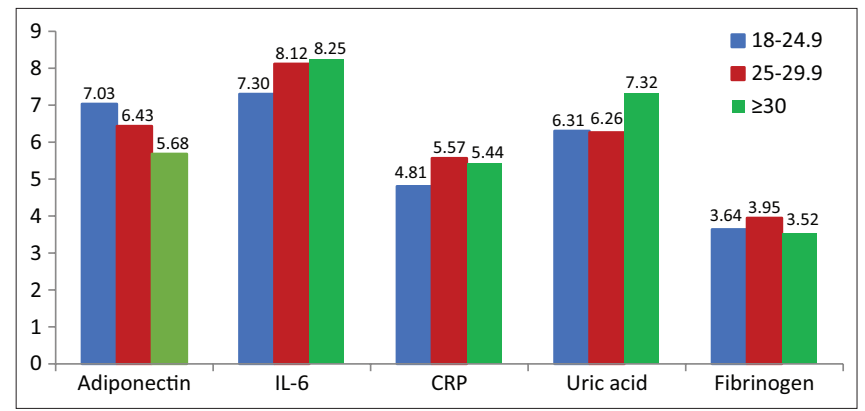

Fig. 3: Effect of body mass index on the level of inflammatory markers in diabetes

patients. Verma et al. [12] reported $34.7 \%$ of pre-diabetic patients to be overweight. Similarly study of Ahmad et al. [13] and Malini et al. [14] demonstrated $36.82 \%$ and $50 \%$ of diabetic patients, respectively, to be overweight. The mean values of BMI and WHR were significantly high in patient groups compared to the control group, while such difference was nor found in the case of WC. In several studies, WC is considered a strong predictor of diabetes in comparison to BMI [15]. However, in studies of Oda and Kawai [16] and Janghorbani and Amini [17], significant differences were not observed in the mean values of BMI which was in contrast to this study, and WC which was similar to this study.

This study also evaluated the levels of inflammatory mediators and their association with obesity indices in patient groups (pre-diabetes and diabetes). Adiponectin (anti-inflammatory adipokine) decreased and pro-inflammatory molecules such as CRP, IL-6, uric, and fibrinogen increased significantly compared to control groups. Our results were in accordance with the previous studies such as that of Upadhyaya et al. [18], Pradhan et al. [19], Kafle and Shrestha [20], and Srikanth et al. [21]. In the case of pre-diabetic subjects, only WHR was correlated 


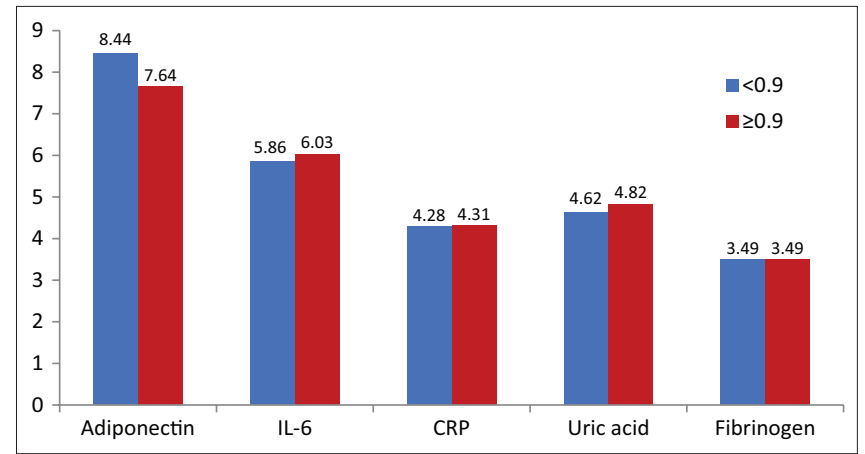

Fig. 4: Effect of waist-hip ratio on the level of inflammatory markers in pre-diabetes

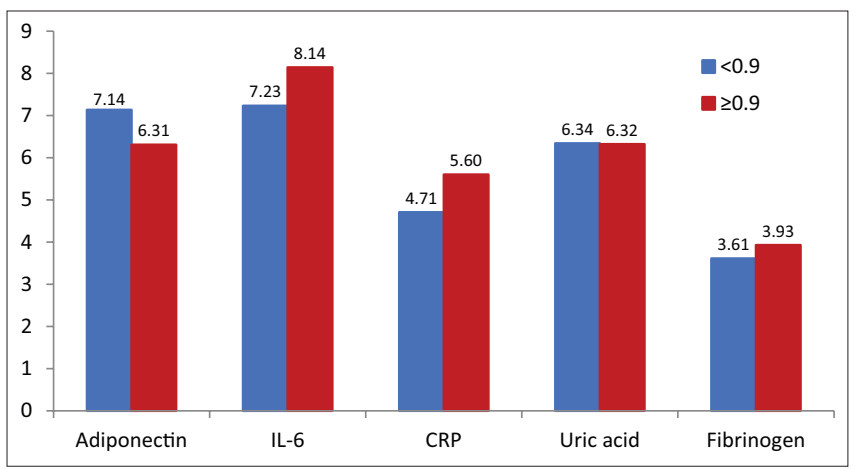

Fig. 5: Effect of waist-hip ratio on the level of inflammatory markers in diabetes

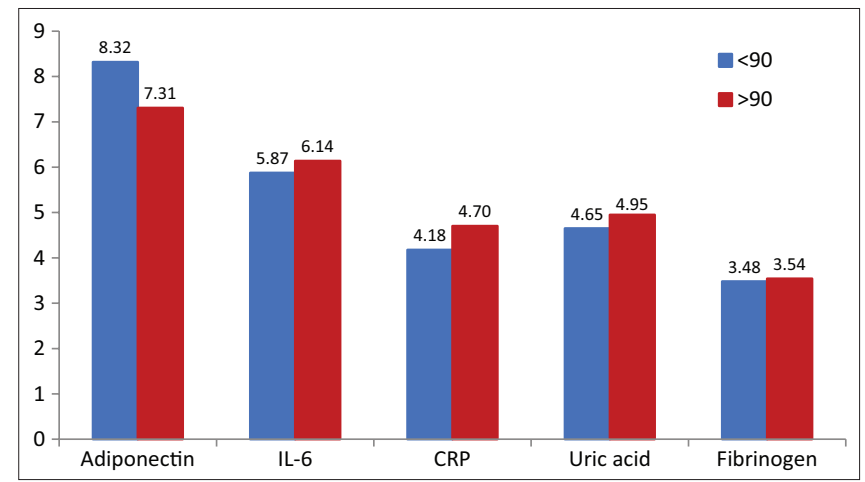

Fig. 6: Effect of waist circumference on the level of inflammatory markers in pre-diabetes

linearly with uric acid and inversely with adiponectin. Both associations were statistically significant. In the case of diabetic subjects, inflammatory mediators correlated significantly with BMI and WC but not with WHR. The previous studies have also reported the significant association of obesity indices, especially BMI with the inflammatory mediators. Kong et al. [22] and Uslu et al. [23] demonstrated an inverse association of adiponectin with BMI in diabetic patients. Likewise, Sachan et al. [24] and Shantaram and Nayak [25] suggested a positive association of CRP with obesity in diabetes. IL- 6 was correlated linearly with BMI and WC in the study of Kluppelholz et al. [26], Malenica et al. [27], and Agrawal et al. [28]. Similarly, Harsoor et al. [29] and Kafle and Shrestha [20] showed a positive association of fibrinogen with BMI while Urbanavicius et al. [30] depicted positive correlation of uric acid with BMI and WHR.

Regarding the mechanistic phenomenon, it has been hypothesized that increased adiposity mediates the upregulation of pro-inflammatory

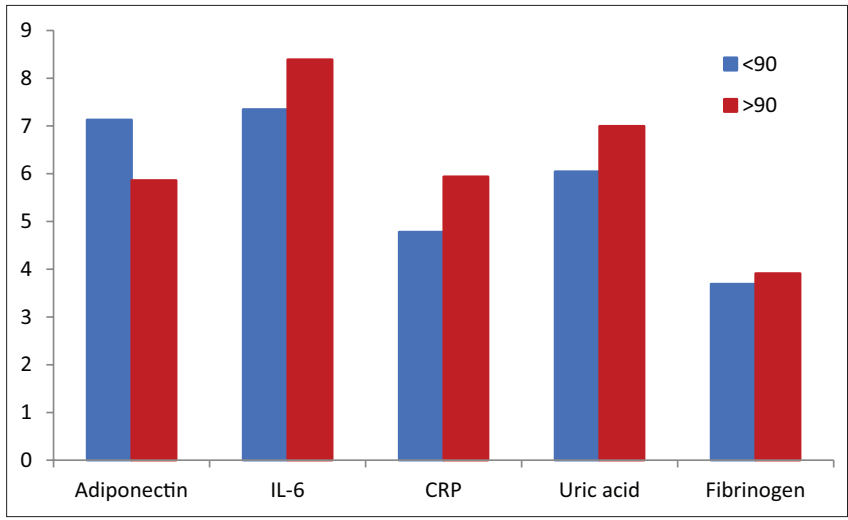

Fig. 7: Effect of waist circumference on the level of inflammatory markers in diabetes

genes through activation of C-Jun- $\mathrm{N}$ terminal kinase and nuclear factor kappa beta, a central regulator of inflammation. These activated genes cause the release of excess amount of cytokines, thereby exacerbating inflammatory responses and leading to insulin resistance which is the major contributor to pre-diabetes and diabetes [31].

\section{CONCLUSION}

The result of our study indicated the significant association of inflammatory mediators with markers of obesity like BMI, WHR, and WC in pre-diabetes and diabetes. Both obesity and inflammation are important risk factors of diabetes and CVDs in pre-diabetic and diabetic patients. This study though simple and conducted on a small sample size can explicate the adverse outcomes of obesity in hyperglycemic patients. Further, this study could be useful in identifying the pre-diabetic and diabetic individuals at high risk so that early intervention by a change in lifestyle, weight loss, and improved dietary habit along with the treatment may prevent the associated complications. Since pre-diabetes is the final gateway to prevent the progression to diabetes and future complications timely management of obesity in the pre-diabetic state may fruitful. However, further elaborated studies with larger sample size are also suggested. Researches on therapeutic approaches which can decrease inflammatory mediators and increase anti-inflammatory mediators are encouraged so that the incidence of obesity-induced inflammatory complications may be alleviated in hyperglycemic patients.

\section{AUTHORS' CONTRIBUTION}

Dr. Pradeep Kumar gave the idea of research work and coordinated in the analytical process. Shailaza Shrestha performed the biochemical analysis and formatted the research article. Dr. Preeti Sharma and Dr. Mahendra Prasad contributed to article proofreading and research guidance. The final manuscript was approved by all the authors.

\section{CONFLICTS OF INTEREST}

None

\section{REFERENCES}

1. Goyal R, Faizy AF, Siddiqui SS, Singhai M. Evaluation of TNF- $\alpha$ and IL-6 levels in obese and non-obese diabetics: Pre-and postinsulin effects. N Am J Med Sci 2012;4:180-4.

2. Saad EA, Habib SA, Refai WA, Elfayoumy AA. Malondialdehyde, adiponectin, nitric oxide, $\mathrm{C}$-reactive protein, tumor necrosis factoralpha and insulin resistance relationships and inter-relationships in Type 2 diabetes early stage. Is metformin alone adequate in this stage? Int J Pharm Pharm Sci 2017;9:176-81.

3. Sidossis L, Kajimura S. Brown and beige fat in humans: Thermogenic adipocytes that control energy and glucose homeostasis. J Clin Invest 2015;125:478-86.

4. Antonopoulos AS, Margaritis M, Coutinho P, Shirodaria C, Psarros C, Herdman L, et al. Adiponectin as a link between Type 2 diabetes and 
vascular NADPH oxidase activity in the human arterial wall: The regulatory role of perivascular adipose tissue. Diabetes 2015;64:2207-19.

5. Nikolajczyk BS, Jagannathan-Bogdan M, Shin H, Gyurko R. State of the union between metabolism and the immune system in Type 2 diabetes. Genes Immun 2011;12:239-50.

6. Ray A, Huisman MV, Tamsma JT, Research and Writing-group, van Asten J, Bingen BO, et al. The role of inflammation on atherosclerosis, intermediate and clinical cardiovascular endpoints in Type 2 diabetes mellitus. Eur J Intern Med 2009;20:253-60.

7. Fantuzzi G. Adipose tissue, adipokines, and inflammation. J Allergy Clin Immunol 2005;115:911-9.

8. Vinkatesh G, Jayprakash A, Swathi KS. The effect of sun light exposure on prediabetic patients in South Indian population. Int J Pharm Pharm Sci 2014;6:107-10

9. Guh DP, Zhang W, Bansback N, Amarsi Z, Birmingham CL, Anis AH, et al. The incidence of co-morbidities related to obesity and overweight: A systematic review and meta-analysis. BMC Public Health 2009;9:88.

10. Cornier MA, Després JP, Davis N, Grossniklaus DA, Klein S, Lamarche B, et al. Assessing adiposity: A scientific statement from the American heart association. Circulation 2011;124:1996-2019.

11. Shanmugam N, Reddy MA, Guha M, Natarajan R. High glucoseinduced expression of proinflammatory cytokine and chemokine genes in monocytic cells. Diabetes 2003;52:1256-64.

12. Verma ML, Verma V, Srivastava A. Prevalence of pre-diabetes among the general population in a tertiary care hospital in North India. Indian J Basic Appl Med Res 2017;6:433-8.

13. Ahmad J, Masoodi MA, Ashraf M, Rashid R, Ahmad R, Ahmad A, et al. Prevalence of diabetes mellitus and its associated risk factors in age group of 20 years and above in Kashmir, India. Al Ameen J Med Sci 2011;4:38-44.

14. Malini DS, Sahu A, Mohapatro S, Tripathy R. Assessment of risk factors for development of Type-2 diabetes mellitus among working women in Berhampur, Orissa. Indian J Community Med 2009;34:232-6.

15. Inter Act Consortium, Langenberg $C$, Sharp SJ, Schulze MB, Rolandsson O, Overvad $\mathrm{K}$, et al. Long-term risk of incident Type 2 diabetes and measures of overall and regional obesity: The EPICinterAct case-cohort study. PLoS Med 2012;9:e1001230.

16. Oda E, Kawai R. Comparison among body mass index (BMI), waist circumference (WC), and percent body fat $(\% \mathrm{BF})$ as anthropometric markers for the clustering of metabolic risk factors in Japanese. Intern Med 2010;49:1477-82.

17. Janghorbani M, Amini M. Comparison of body mass index with abdominal obesity indicators and waist-to-stature ratio for prediction of Type 2 diabetes: The Isfahan diabetes prevention study. Obes Res Clin Pract 2010;4:e1-82.
18. Upadhyaya S, Kadamkode V, Mahammed R, Doraiswami C, Banerjee G. Adiponectin and IL-6: Mediators of inflammation in progression of healthy to Type 2 diabetes in Indian population. Adipocyte 2014;3:39-45.

19. Pradhan AD, Manson JE, Rifai N, Buring JE, Ridker PM. C-reactive protein, interleukin 6 , and risk of developing Type 2 diabetes mellitus. JAMA 2001;286:327-34

20. Kafle DR, Shrestha P. Study of fibrinogen in patients with diabetes mellitus. Nepal Med Coll J 2010;12:34-7.

21. Srikanth S, Lavanya Y, Sushma K. Relationship between serum uric acid and BMI in pre-diabetics and Type II diabetics in rural population a pilot study. Biomed Rev J Basic Appl Med Sci 2014;1:41-7.

22. Kong SE, Kang YE, Joung KH, Lee JH, Kim HJ, Ku BJ, et al. Plasma adiponectin levels in elderly patients with prediabetes. Endocrinol Metab (Seoul) 2015;30:326-33.

23. Uslu S, Kebapçi N, Kara M, Bal C. Relationship between adipocytokines and cardiovascular risk factors in patients with Type 2 diabetes mellitus. Exp Ther Med 2012;4:113-20.

24. Sachan P, Khan MM, Pisharody I. A cross sectional study showing association of C-reactive protein (C-RP) with prediabetes and diabetes in Indian population. J Biol Chem Res 2017;34:683-7.

25. Shantaram M, Nayak S. Relationship of hs-CRP level in diabetic persons free from micro and macrovascular disease. Int J Res Dev Pharm Life Sci 2014;3:1070-3.

26. Kluppelholz B, Thorand B, Koenig W, de Las Heras Gala T, Meisinger $\mathrm{C}$, Huth $\mathrm{C}$, et al. Association of subclinical inflammation with deterioration of glycaemia before the diagnosis of Type 2 diabetes: The KORA S4/F4 study. Diabetologia 2015;58:2269-77.

27. Malenica M, Šilar M, Dujić T, Bego T, Semiz S, Škrbo S, et al. Importance of inflammatory markers and IL-6 for diagnosis and follow up of patients with Type 2 diabetes mellitus. Med Glas (Zenica) 2017; $14: 169-75$

28. Agrawal A, Hegde A, Yadav C, Ahmad A, Manjrekar PA, Rukmini MS. IL-6 and impaired fasting glucose. Indian J Biochem Biophys 2018;55:424-8.

29. Harsoor S, Kinagi A, Ananta A. Correlation of plasma fibrinogen with blood pressure, BMI, lipid profile and glycemic status in Type 2 DM. J Evol Med Dent Sci 2014;3:14615-27.

30. Urbanavicius V, Abraitiene A, Vitkus D, Borovkiene R, Kucinskiene ZS. Adiponectin and uric acid in pre-diabetes and early Type 2 diabetes mellitus. Acta Med Litu 2015;15:81-7.

31. Rajala MW, Scherer PE. Minireview: The adipocyte at the crossroads of energy homeostasis, inflammation, and atherosclerosis. Endocrinology 2003; $144: 3765-73$ 